\title{
Psycho-Ecological Systems Model: A Systems Approach to Planning and Gauging the Community Impact of Community-Engaged Scholarship
}

\author{
Roger N. Reeb \\ University of Dayton
}

Susan F. Folger

Ohio University

Laura Stayton

Western Michigan University

Bernadette O'Koon

Wright State University School of

Professional Psychology

\author{
Nyssa L. Snow-Hill \\ University of South Carolina
}

\author{
Anne L. Steel \\ University of Nebraska-Lincoln
}

\author{
Charles A. Hunt \\ University of Dayton
}

Zachary Glendening

Vanderbilt University

\begin{abstract}
This article presents the Psycho-Ecological Systems Model (PESM) - an integrative conceptual model rooted in General Systems Theory (GST). PESM was developed to inform and guide the development, implementation, and evaluation of transdisciplinary (and multilevel) community-engaged scholarship (e.g., a participatory community action research project undertaken by faculty that involves graduate and/or undergraduate students as service-learning research assistants). To set the stage, the first section critiques past conceptual models. Following a description of GST, the second section provides a comprehensive description of PESM, which represents an integration of three conceptual developments: the ecological systems model (Bronfenbrenner, 1979), the biopsychosocial model (Kiesler, 2000), and the principle of reciprocal determinism (Bandura, 1978). In the third section, we discuss implications of PESM for community-based research. A greater emphasis on the development of integrative conceptual frameworks may increase the likelihood that community-based research projects will: (a) address complex questions; (b) develop and implement efficacious (and sustainable) transdisciplinary (and multilevel) projects; (c) assess constructs at multiple levels using a blend of quantitative and qualitative approaches; and (d) utilize multiple research designs and methods to systematically examine hypotheses regarding a project's influence on outcome variables and process variables.
\end{abstract}

Psycho-Ecological Systems Model:

A Systems Approach to Planning and Gauging the Community Impact of Community-Engaged Scholarship

"There are only a few models developed to measure the community impact of higher education civic engagement" (Stoecker, Beckman, \& Min, 2010 , p. 187), and there is a dearth of research documenting community outcomes of communityengaged scholarship. In general, Stoecker et al. (p. 177) argued: "There is very little evidence ... that institutions are systematically documenting the outcomes of [community-engaged scholarship] contributions and, consequently, little evidence that it matters ... Such work can indeed make a contribution, but the evidence of effectiveness is scant." Similarly, Reeb and Folger's (2013) review of research on community outcomes of service- learning projects concluded: "There is a significant lack of research exploring community outcomes of service-learning, representing a surprising void in the literature." Development of integrative conceptual frameworks may increase the likelihood that community-engaged scholarship will: (a) address complex questions; (b) develop and implement efficacious (and sustainable) transdisciplinary (and multilevel) projects; (c) assess constructs at multiple levels using a blend of quantitative and qualitative approaches; and (d) utilize multiple research designs and methods to systematically examine hypotheses regarding the influence of a project on outcome variables and process variables.

Reeb and Folger (2013) introduced an early version of the Psycho-Ecological Systems Model (PESM) - a conceptual framework developed to inform and guide the development, implementation, and evaluation of transdisciplinary (and multilevel) 
community-based research projects. In this article, we delineate the underlying theoretical foundation of PESM - General Systems Theory (GST), fully describe the integrative PESM - including a new feature (temporal dimension) added to the earlier version, and discuss the implications of the model for community-engaged scholarship. To set the stage, the first section reviews and critiques past conceptual models of community-engaged scholarship in light of several key criteria. In the second section, we describe the theoretical foundation of PESM (i.e., GST), and we show that PESM represents an integration of three conceptual developments: the ecological systems model (Bronfenbrenner, 1979), the biopsychosocial model (Kiesler, 2000), and the principle of reciprocal determinism (Bandura, 1978). The third section provides an overview of the integrative PESM. Finally, in the fourth section, we discuss implications of PESM for community-engaged scholarship.

\section{Conceptual Models for Community-Engaged Scholarship: Overview and Critique}

\section{Overview of Conceptual Models}

Van de Ven's (2007) Diamond Model. Van de Ven defined community-engaged scholarship as "a participative form of research for obtaining the different perspectives of key stakeholders (researchers, users, clients, sponsors, and practitioners) in studying complex problems" (p. 9). Consideration of multiple perspectives allows researchers to "step outside of themselves" (p. 10) to engage in four sets of research activities: (a) problem formulation, judged by the criterion of relevance (i.e., the extent to which insights enhance our understanding of the problem); (b) theory building, judged by the criterion of validity (i.e., whether or not a theory is empirically- and conceptually-verified); (c) Research design, judged by the criterion of truth (verisimilitude) (i.e., whether or not the research design and method meet standards of the scientific community); and (d) problem solving, judged by the criterion impact (i.e., the extent to which a project resolves a problem). Van de Ven also emphasized the criterion of cohesion - the degree to which results have "applicability beyond the situation" (p. 105). Finally, he identified two types of complementary research models: variance models ("what causes what") and process models ("how things develop and change over time") (p. 146).

Bailis and Ganger's Model. Bailis and Ganger (2006) provided a "preliminary . . . two-tiered . . . framework for understanding . . . community impact ...” (pp. 70-71): First, the individual level considers (a) impacts on service-learning students (e.g., civic development), (b) impacts on recipients of direct service (e.g., well-being); and (c) impacts on community (e.g., attitudes of community members). Second, the institutional level considers: (a) impacts within the agency (e.g., attitudes of staff); (b) impacts on the agency's relationship with service recipients (e.g., quality of service provision); and (c) impacts on the agency's relationship to community (e.g., partner agencies). The authors concluded that: "a comprehensive analysis of community impact . . . should . . . include many interrelated and complementary aspects of community" (p. 71).

Marullo, Cook, Willis, \& Rollins' Model (2003). This three-dimensional model emphasized multidimensional assessment. The first dimension is level of analysis targeted by a change initiative: (a) micro (individual outcomes); (b) meso (outcomes for programs, organizations, or communities); and (c) macro (outcomes for "broader structures . . . such as social policies, local, state and federal laws, and community systems") (p. 62). The second dimension, goals to be assessed, specifies four purposes: (a) enhancing capacity of individuals or organizations; (b) increasing efficiency of an organization's operations (improving service delivery); (c) empowering constituents to be effective change agents on their own behalf; and (d) altering policies or structures to benefit disadvantaged individuals. The third dimension focuses on processes (short-term outcomes) and effects (long-term outcomes). Assessment of process refers to examining underlying mechanisms of a program seeking to bring about social change and/or delivery of services, whereas assessment of effects refers to "document[ing] the extent to which the desired outcomes are achieved" (p. 63). A four-step assessment feedback loop was described that (a) starts with "a social change initiative that seeks to improve the quality of life and/ or opportunities of a disadvantage group" (step 1); (b) determines "whether the actions are . . . being undertaken as intended and whether they are having the anticipated effects" (step 2); (c) utilizes "assessments . . . designed to create information that answers ... questions regarding ... processes and effects of . . . change efforts" (step 3); (d) draws "conclusions to respond to the initial questions" (step 4); and (e) employs "findings . . . as input to reevaluate and ... revise the social change initiative ... to improve its effectiveness" (back to step $1)$.

PAR Outcomes Project Model. Stoecker et al. (2010) described a model developed by international participants of the Participatory Action Research Outcomes Project (2007). Similar to Marullo et al. 
(2003), they conceptualized impact at different levels: (a) individual (gaining access to, and utilizing, power and resources); (b) organizational (increasing capacity or effectiveness); and (c) "broader social change outcomes" at community and societal levels. They argued that broader social outcomes develop as: "other communities hear about successful projects and adapt them for their own uses" or "policy makers devise new policies after hearing about the outcomes of efforts in other places" (2010, p. 191). Relative to broader impacts at community or societal levels, more direct outcomes at individual or organizational levels are viewed as more easily identified and measured. They argued that long-term assessment of broader social outcomes is overlooked in project development, due to excessive concerns of institutions of higher education with "narrow contributions to civic engagement" (p. 190) or the "part of the process that concerns the institution's short-term self-interest" (p. 191). Viewing time as a "crucial variable," they recommended that assessment (a) initially focus on individual or organizational outcomes and (b) then identify and measure broader social outcomes as they eventually occur over time.

\section{Critique of Conceptual Models on Several Key Criteria}

Incorporating multiple systems. For a complex community problem, it may be necessary for a community-engaged scholarship project to employ a multilevel intervention, which also requires assessment of process and outcome variables across systems (levels of analysis). In past models, certain qualitatively distinct systems seemed neglected, perhaps obscuring processes and outcomes connected to those systems. In other words, if a model fails to represent the full array of systems, then process and outcome variables in systems other than those systems targeted by an intervention may be overlooked, especially processes and outcomes that are subtle, unintended, or gradually emerging over time. None of the models critiqued in this article clearly identified subsystems within the individual (e.g. vulnerabilities or resiliencies), which are sometimes necessary targets for community interventions. Bailis and Ganger (2006) distinguished between individual- and institutional-level impacts. Marullo et al. (2003) and Stoecker et al. (2010) recognized a wider range of systems, but they did not incorporate an international/global system.

To provide a bird's eye view or a broad framework - to recognize the wide array of existing systems beyond the individual, the earliest iterations of PESM, (see Reeb \& Folger, 2010, 2013), em- phasized the need to incorporate Bronfenbrenner's (1979) ecological systems: microsystems (e.g., family, peer, or work); mesosystems (interrelationships among microsystems); exosystems (e.g., school board, local government); and macrosystems (e.g., culture, federal government, national economy). [A recent publication (Wells, 2017) also considered general implications of Bronfenbrenner's model for the scholarship of teaching and learning.] PESM augments Bronfenbrenner's conceptualization by adding the supra-macrosystem in order to represent international or global influences, including international community-engaged scholarship (Niehaus \& Crain, 2013). Further, to represent subsystems within the individual (vulnerabilities and resiliencies), which are sometimes targeted by community interventions, PESM integrates the biopsychosocial approach (Kiesler, 2000). PESM's multisystem approach is fully described later.

Recognizing reciprocal interactions among systems. Models tend use the term level of analysis as opposed to the term system, risking the misinterpretation that ramifications of change at one level are limited to that particular level. Further, there is some confusion in the Marullo et al. model (2003) regarding the correspondence between levels of analysis and types of outcomes; that is, it placed levels of analysis and types of outcomes on separate axes, with the implication that each type of outcome is possible at each level of analysis. But as Stoecker et al. (2010) noted, this approach is problematic because the outcome of altering policies does not logically coincide with the individual level.

Because PESM is rooted in GST, it inherently emphasizes the interdependency among complex systems (from individual to international/global levels), as fully described later. In addition, PESM incorporates Bandura's (1978) principle of reciprocal determinism to assist in explaining bidirectional influences among personal factors, behavior, and environment. The biopsychosocial approach, as integrated in PESM, posits developmental pathways wherein reciprocal interactions occur between internal individual factors (e.g., vulnerabilities and resiliencies) and external factors (e.g., risks and resources) to influence outcomes across systems and over time.

Guiding the development of transdisciplinary projects. Consistent with new approaches to epistemology that emphasize the necessity to incorporate multiple perspectives in the construction of knowledge (e.g., Mode 2 Approach; see Gibbons, Limoges, Nowotny, Schwartzman, Scott, \& Trow, 1994), Van de Ven's (2007) model stands out in emphasizing the need for community-engaged scholars 
to seek multiple perspectives, and this approach is also central to PESM. That is, with an emphasis on interacting complex systems, PESM sets the stage for community-engaged scholars to seek input from multiple perspectives, such as faculty across disciplines as well as community stakeholders. Hence, the term transdisciplinary is more precise than interdisciplinary. While interdisciplinary involves "several academic disciplines . . . that . . . cross subject boundaries to ... solve a common ... goal ...," transdisciplinary means to "integrate ... different disciplines and non-academic participants ... to [accomplish] a common goal" (Tress, Tress, \& Fry, 2006, p. 17). PESM recognizes that obtaining input from multiple perspectives is critical for successful community-engaged scholarship, and this issue is discussed in more detail later.

Distinguishing among project evaluation variables. Stoecker et al. (2010) made a helpful distinction between outputs and outcomes. For example, in a project assisting homeless people in transitioning out of homelessness, the number of homeless individuals participating in the project is an output, whereas the level of progress of individuals in securing stable housing is an outcome. Stoecker et al. concluded: "For too long, funders and community organizations have [accepted] the achievement of outputs, rather than outcomes, as a measure of project success" (p. 186). Further, the distinction between outcome and process variables is often overlooked. Although Marullo et al. (2003) distinguished between process and outcome, they did not emphasize the need to examine processoutcome links. However, Van de Ven's (2007) model recognized process-outcome connections, and Stoecker et al. (2010) noted, "The reason to analyze process . . . is to understand its relationship to effects (p. 188)." In general, most models do not distinguish among output, outcome, and process variables, and none of the models identified the vast array of outcome and process variables that are pertinent to community-engaged scholarship. PESM's broad (multisystem) framework facilitates the identification of project evaluation variables, and in a later section, we carefully delineate the numerous types of outcome and process variables.

Representing the temporal dimension. The Stoecker et al. (2010) model is unique among past models in emphasizing the dimension of time. However, their consideration of time appears to be limited to one issue: "historical progression . . . from individual impacts to societal-wide impacts" (p. 191) following project implementation. While the potential progression (or broadening) of a project's influence over time is a critical concern, PESM also recognizes other time-related factors pertinent to community-engaged scholarship projects, as delineated in a later section.

\section{Theoretical Foundation and Components of PESM}

With GST as a foundation, PESM integrates three conceptual developments: the ecological systems approach (Bronfenbrenner, 1979), the biopsychosocial approach (Kiesler, 2000), and the principle of reciprocal determinism (Bandura, 1978).

\section{General Systems Theory: \\ Contextual Foundation for PESM}

According to Ludwig Von Bertalanffy, the founder of GST, "the notion of systems is as old as European philosophy" (1972, p. 407). In 1968, he formally introduced GST:

\begin{abstract}
There is a general tendency towards integration in the various sciences, natural and social ( $p$. 38) ... Such integration seems to be centered in a general theory of systems (p. 38) . . It seems, therefore, that a general theory of systems would be a useful tool [for] providing ... . models that can be used in, and transferred to, different fields (p. 34) ... General systems theory ... is a general science of "wholeness" ... (p. 37) ... [which] brings us nearer to the goal of the unity of science . . . [and] . . can lead to a much-needed integration in scientific education (p. 38).
\end{abstract}

Anderson, Carter, and Lowe (2007, p. 294) define system as "an organized whole made up of components that interact in a way distinct from their interaction with other entities, and that endures over some period of time." (p. 294). They go on to say that GST has four underlying characteristics. First, it is comprehensive - it "offers greater potential for description and integration of seemingly disparate theories into a single framework" (p. xix). Because GST is a tool for integration, Boulding (1956) called it the "skeleton of science" (p. 208). Second, GST imparts suggestive leads for all sectors of human behavior, and for the reciprocal transactions that occur among sectors. Third, GST has "the potential to provide a common language to various disciplines, both within and across disciplines" (p. xix). A fourth characteristic is parsimony; that is, GST allows us to incorporate diverse (and disparate) theories of human behavior, research methods, and procedures of practice within one common, coherent framework that can be mastered by researchers and practitioners across disciplines.

Systems exist at multiple levels (e.g., person, 
family, neighborhood, community, society, culture, international/global); that is, subsystems are nested within systems which, in turn, are embedded within more complex, higher order systems (suprasystems). A central concept is the holon, as coined by Koestler (1967): “. . . there is no satisfactory word in our vocabulary to refer to . . . sub-wholes . . . The term that I would propose is 'holon', from the Greek holos $=$ whole, with the suffix on which, as in proton or neutron, suggests a particle or part" (p. 48). Thus, a holon is an entity (system) that is itself a whole and, simultaneously, part of a whole. Holons are embedded (integrated) within a holarchy. While the terms holarchy and hierarchy are often used interchangeably, holarchy best conveys the intended emphasis on bidirectional relationships among lower and higher holons, as opposed to the hierarchy-related implication of control from the top. "Any system is by definition both part and whole... No single system is determinant, nor is system behavior determined at only one level" (Anderson et al., 2007, p. 5, emphasis in the original).

Within a holarchy, each holon is a unique whole, with some degree of autonomy (independence) and, as a self-contained whole, operates by its own code of rules to maintain adaptive functioning and express individuality. This is referred to as the selfassertive tendency. At the same time, each holon is integrated within a larger whole and, while the holon is dependent upon the larger system, it also contributes to the maintenance of the larger system. This is referred to as the integration tendency. There is significant cohesion among components of a holon (e.g., members within a family), with some degree of separation (semi-permeable boundaries) between holons (e.g., family and community) (see Anderson et al., 2007).

In research or practice, the system perceived as needing a social change initiative is referred to as the focal system or target system. To fully understand any given focal system, the observer must also attend to the components (subsystems) as well as the suprasystem of which it is a part. Hence, GST is often referred to as contextual, interactional, or perspectivistic. Finally, a feedback cycle refers to the process in which a holon (subsystem) receives internal or external information (a form of energy) and adapts accordingly. Adaptation involves both accommodation (the system modifies itself to incorporate new information) and assimilation (the new information is interpreted and integrated within the system). In this way, systems within a holarchy interact and influence one another in a pattern of reciprocal determinism, thereby promoting a process of self-regulation necessary for a state of balance (also called equilibrium, ho- meostasis, or steady state). Balance is established by two complementary tendencies: morphostasis (structure maintaining) and morphogenesis (structure changing). GST provides a rich contextual foundation for the development of PESM as a guide for community-engaged scholarship (see Anderson et al., 2007).

\section{Overview of Theoretical Approaches Integrated in PESM}

Ecological approach. Consistent with GST, Bronfenbrenner (1979) viewed the individual as embedded in a holarchy of interdependent systems (i.e., holons) at increasingly broader levels of analysis (also see Hawe, 2017). The microsystem is "a pattern of activities, roles, and interpersonal relations experienced by the developing person in a given setting ..." (p. 22). Examples include the dynamics within a peer group or family. Bronfenbrenner's approach is unique in showing how microsystems are embedded within the mesosystem, which is "a system of microsystems" consisting of "interrelationships among two or more settings in which the developing person actively participates" (p. 25). That is, at any point in time, a person participates in numerous settings that are potentially interdependent, as illustrated by the reciprocal relationships among the following: family and school; peer group and family; family and work; different social agencies; and church and neighborhood. The mesosystem concept is useful in conceptualizing interventions; for instance, in communityengaged scholarship, consider the potential benefit of a meso-system intervention that fosters collaboration between two microsystems: (a) a homeless shelter and (b) a health clinic for people without health insurance.

According to Bronfenbrenner (1979), the exosystem is comprised of "one or more settings that do not [or may not] involve the developing person as an active participant, but in which events occur that affect, or are affected by, what happens in the setting containing the developing person" (p. 25), such as extended family, family member's workplace, local school board, local government, business and industry, planning commissions, and social service agencies. Finally, the macrosystem comprises allembracing influences, such as beliefs, values, customs, fashions, rituals, habits, or political dynamics, at the socio-cultural level. Bronfrenbrenner viewed the macrosystem as fairly comprehensive; that is, it includes all "consistencies . . . of lowerorder systems (micro, meso, and exo) that exist, or could exist, . . . at the . . . subculture or the culture, along with any belief system or ideology underlying such consistencies" (p. 26). Bronfenbrenner 
viewed the consistencies (patterns) as blueprints for activities that maintained (stabilized) the environment, though he recognized that the influence of the so-called blueprints does vary (to some extent) across demographic groups (e.g., ethnic, socioeconomic, religious, educational level, and so on). Notice that, as Bronfenbrenner discussed these macrosystem blueprints, he included the expression "or could exist" (p. 26) and thereby acknowledged the possibility that an initiative (e.g., a communityengaged scholarship project) could alter blueprints for action (as necessary) for enhanced adaptation (or improvement of wellbeing in community members). PESM adds the supra-macrosystem to capture the international/global system, which is critical given (a) the potential effects of global events on all lower-lever systems and (b) a growing interest for international community-engaged scholarship (Niehaus \& Crain, 2013). Community-engaged scholarship interventions (and their outcomes) may occur in any system or in multiple systems (as in multilevel interventions).

Finally, to acknowledge the fact that ecological systems change over time, Bronfenbrenner (1993) postulated the chronosystem, which refers to events over time that influence an individual's life, including (a) events in one's private life (e.g., divorce) and (b) sociohistorical events (e.g., civil rights movement, technological advancements). We added a temporal dimension to PESM to conceptualize how changes in a community-engaged scholarship project (or its outcomes) may develop over time. While influenced by Bronfenbrenner's chronosystem concept, PESM's temporal dimension is tailored to issues revolving around communityengaged scholarship.

In sum, the ecological component of PESM is helpful in (a) planning and implementing multilevel interventions and (b) evaluating outcomes (and processes underlying outcomes) as they emerge and interact across systems and over time.

Biopsychosocial approach. The subsection above showed that Bronfenbrenner's (1991) approach views the developing community member as embedded within increasingly broader (and interactive) systems. It is also critical to conceptualize internal subsystems in community members that influence their (a) tendencies in reacting to contextual factors and (b) capacities for creating change in proximal settings (or even broader systems). These subsystems represent potential intervention targets, and outcome measures at this level are readily available (e.g., Robinson, Shaver, \& Wrightsman, 1991). In general, the biopsychosocial approach and the ecological approach complement one another when integrated within PESM.
A biopsychosocial approach (Kiesler, 2000) examines the ways in which specific internal factors (vulnerability and resiliency factors) and specific external factors (risk and protective resource factors) interact during a developmental period to influence a community member's health, quality of life, or wellbeing. A vulnerability is an internal predispositional factor (e.g., low self-esteem, maladaptive personality traits, mental illness, substance abuse) that increases a person's likelihood of developing general problems in living and/or some particular problem (e.g., homelessness). A risk is any external condition or situation (e.g., maladaptive family system, traumatic events) that, when experienced by a person, increases the likelihood of the person developing general problems in living and/or some particular problem (e.g., homelessness). A resiliency factor is any internal attribute (e.g., high intelligence, adaptive coping skills, good health) that promotes adaptation by enabling a person to overcome (transcend) stressors, obstacles, and other negative life events. Kiesler (2000) noted that, when faced with a negative life event, a resiliency attribute enhances the person's "tendency to rebound or recoil, to spring back, or [to possess] the power to recover (p. 148)." A protective resource is any external factor (e.g., social support, community resources) that promotes health, quality of life, or wellbeing by strengthening resiliency factors and/ or decreasing (or defending against) the negative influences of risk and vulnerability factors.

In considering the interactions between internal factors (vulnerabilities and resiliencies) and external factors (risks and protective resources), the concept of developmental pathways is central to a biopsychosocial approach. To explain the notion of developmental pathways, we need to consider the principles of equifinality and multifinality as well as the concept of developmental periods (Cicchetti \& Cohen, 1995). The principle of equifinality refers to the finding that, as internal and external factors interact throughout development, there is no one specific pathway to any particular outcome, because a variety of developmental pathways may result in similar outcomes. The principle of multifinality suggests that a given internal or external factor may contribute to a wide variety of outcomes, depending on how the factor interacts with (a) the individual's present developmental period and (b) the aggregate of other (internal and external) factors. Each developmental period (infancy, early childhood, elementary school age, adolescence, adulthood, old age) consists of a distinctive set of abilities, limitations, demands, and tasks (Kiesler, 2000), which (a) make a person more or less sensitive to certain environmental factors, (b) influence 
the person's vulnerability or resiliency in the face of a particular negative event, and (c) determine one's level of readiness to benefit from particular types of experience. For instance, within a critical period (see classic article by Colombo, 1982), there is an intensified sensitivity to particular stimuli in the environment. Normal development in some domains (e.g., language acquisition) depend upon exposure to certain stimuli (e.g., language) during a critical period (see classic work by Lenneberg, 1967). Conversely, during other types of critical periods, certain stimuli can have a very harmful influence on a person's development (e.g., the stage of embryo development influences susceptibility to teratogens).

In designing community-engaged scholarship projects, the following points should be considered: (a) individual factors (resiliency and vulnerability factors) represent potential intervention targets for projects, (b) outcome measures for person-related constructs are available (e.g., Robinson et al., 1991), (c) community members may experience the same outcome (e.g., homelessness) via diverse developmental pathways, and (d) a community member's current developmental period influences his/her receptivity to, and readiness to benefit from, particular experiences or interventions.

Bandura's Principle of Reciprocal Determinism. As explained earlier, GST postulated bidirectional relationships among lower and higher holons embedded within a holarchy, with a feedback cycle promoting adaptation (and a state of balance) via the complementary processes of accommodation and assimilation. Likewise, Bronfenbrenner proposed a "principle of interconnectedness" (p. 7) or "reciprocity" (p. 22), meaning that, through a "process of mutual accommodation," any interaction between ecological systems is "two-directional" (p. 22) in nature. PESM complements this notion of interdependence among ecological systems by incorporating Bandura's (1978) principle of reciprocal determinism, which is a straightforward explanation of changes that occur due to personenvironment interactions. This principle maintains that person-related factors, behavior, and proximal environmental factors transact (constantly influence one another) in a bidirectional fashion. Bandura (1978) writes:

In the ... process of reciprocal determinism, behavior, internal personal factors, and environmental influences all operate as interlocking determinants of each other ... in a triadic reciprocal interaction ... For example, people's efficacy ... expectations influence how they behave, and the environmental effects created by their actions in turn alter their expecta- tions ... (p. 346) . . . Because personal and environmental determinants affect each other in a reciprocal fashion, attempts to assign causal priority to these two sources of influence reduce to the chicken-or-egg debate (p. 354).

A corrective change in one system (individual, environment, or behavior) may reverberate and create a self-perpetuating cycle of corrective changes among all three systems. As already noted, concepts associated with the biopsychosocial model (e.g., critical periods) also assist us in understanding person-environmental interactions. While the principle of reciprocal determinism focuses on the person's proximal environment, PESM (in line with GST and Bronfenbrenner's view) emphasizes that the proximal environment is embedded within (and influenced by) broader ecological systems.

In discussing the principle of reciprocal determinism, Bandura (1978) argues: "It is true that behavior is influenced by the environment, but the environment is partly of a person's own making ..." (p. 345). That is, to some considerable degree - and in positive or negative ways (and intentionally or unintentionally), a person plays a role in the construction of her or his own environment, and Bandura placed a significant emphasis on human agency (e.g., self-efficacy) in discussions of the principle of reciprocal determinism. Given that the principle of reciprocal determinism is incorporated in PESM, it is noteworthy that this acknowledgement of the role of human agency coincides with the conviction among community-engaged scholars that community members possess the potential to make meaningful changes in a community (e.g., Harkavy \& Hartley, 2010; Reeb, Folger, Langsner, Ryan, \& Crouse, 2010; also see Bhattacharyya, 2004).). Further, PESM's emphasis on strengthening human agency supports a recommendation that community-engaged scholars strive to develop community interventions that meet criteria of psychopolitical validity (Prilleltensky, 2008), which is described in a later section. For the purpose of the present discussion, it is sufficient to note that one criterion of psychopolitical validity is whether or not a community intervention is successful in empowering (strengthening human agency and/or political power) community members.

\section{The Integrative PESM: A Guide for Community-Engaged Scholarship}

Given our emphasis on incorporating multiple perspectives, a brief comment on the process of developing PESM is warranted. First, with homelessness used as an example of a community prob- 
lem, an interview study was conducted in which a wide range of stakeholders (e.g., university faculty and staff, community professionals) were asked to provide input on an early version of PESM (Reeb \& Folger, 2010; Reeb, Folger et al., 2011). Second, over a number of years, versions of PESM were presented at conferences, including local (Reeb, Majka, Majka, Mason et al., 2011; Reeb, Steel, Mason, Stayton, \& Ufholz, 2011), regional (Reeb, Snow, Susdorf, Thomas, \& Lynn, 2013), national (Reeb, Folger et al., 2011), and international (Reeb \& Folger, 2010; Reeb, Gahimer et al., 2011; Reeb, Gahimer, Snow, \& Glendening, 2013) conferences. In addition, a number of symposia (Reeb, Davidson et al., 2011; Reeb, Majka, Majka, Mason et al., 2011; Reeb et al., 2012) were conducted in which (a) a version of PESM was presented and (b) researchers from different disciplines and universities conceptualized their own research within PESM, while providing recommendations for model modifications. Based on collective input, an earlier version of PESM was introduced within a chapter reviewing community outcomes of servicelearning (Reeb \& Folger, 2013). We continued to seek input on PESM through conference and symposia presentations as the Reeb and Folger (2013) chapter was in press and after its publication (Reeb, Farmer, Glendening, \& Kinsey, 2014; Reeb, Farmer, Glendening, Kinsey, Elvers, Farnsworth et al., 2014; Reeb, Glendening, Farmer, Snow, \& Elvers, 2014; Reeb et al., 2015; Reeb et al., 2016). This process of feedback and revision of PESM, which one conference participant referred to as "a good model for developing a model," resulted in the current iteration (and full description) of PESM, including the addition of a temporal dimension. While we view PESM to be a helpful guide for communityengaged scholars, PESM is an evolving model, and we continue to seek constructive input (e.g., Reeb, O'Koon, Folger, \& Snow, 2017), with a commitment to improving the model (see Figure 1).

Figure 1 represents PESM, which integrates the ecological systems model, the biopsychosocial model, and the principle of reciprocal determinism. In the middle of Figure 1, the letters $P, B$, and $E$ (denoting person factors, behavior, and environment, respectively) are in the shape of a triangle, which is how Bandura routinely illustrates the principle of reciprocal determinism.

The $P$ (person factors) incorporates internal factors of the biopsychosocial model (vulnerabilities, resiliency, and developmental period), whereas external factors of the biopsychosocial model (risks and protective resources) exist across ecological systems. Internal and external factors continually interact throughout development to determine outcomes (e.g., health, quality of life, wellbeing). PESM's developmental pathways are defined by the principle of equifinality (i.e., different pathways can result in similar outcomes) and the principle of multifinality (i.e., effects of a factor are moderated by the aggregate of internal factors, external factors, and developmental period).

Within the PESM, the community member is viewed as a single system (holon) embedded within a holarchy of ecological systems (holons) at progressively broader levels. The ecological systems identified by Bronfenbrenner are incorporated in PESM: the microsystem, the mesosystem, the exosystem, and the macrosystem. Further, PESM adds the supra-macrosystem (Reeb \& Folger, 2013), which refers to international influences (e.g., wars) or global influences (e.g., climate change). In Figure 1, the oval formed by bidirectional arrows is superimposed across ecological systems (with the designation of TIME), which represents PESM's temporal dimension - the notion of interdependence (reciprocal influence) among systems over time. PESM's temporal dimension, which was influenced by Bronfenbrenner's (1993) chronosystem, has implications for community-engaged scholarship, as delineated below.

\section{Implications and Recommendations}

\section{Transdisciplinary and Multilevel Projects}

For a complex community problem (e.g., homelessness), a project may need to provide a multilevel intervention. Given that no one discipline (nor any one particular community stakeholder) is capable of addressing every system, transdisciplinary initiatives are recommended. Further, we recommend participatory community action research (PCAR), as defined by Minkler \& Wallerstein (2003):

... A collaborative approach to research that
equitably involves all partners in the research
process and recognizes the unique strengths
that each brings ... . [PCAR] begins with a
research topic of importance to the communi-
ty with the aim of combining knowledge and
action for social change to improve communi-
ty ... (p. 6)

As noted by Bringle, Reeb, Brown, and Ruiz (2016), "Terms used [somewhat] interchangeably with PCAR include community-based research, community action research, and participatory action research" (p. 39), but one critical point is that we are referring here to research with the community (as opposed to research on or $\underline{i n}$ the community), as nicely captured by the adage "nothing 
Figure 1

Psycho-Ecological Systems Model (PESM).

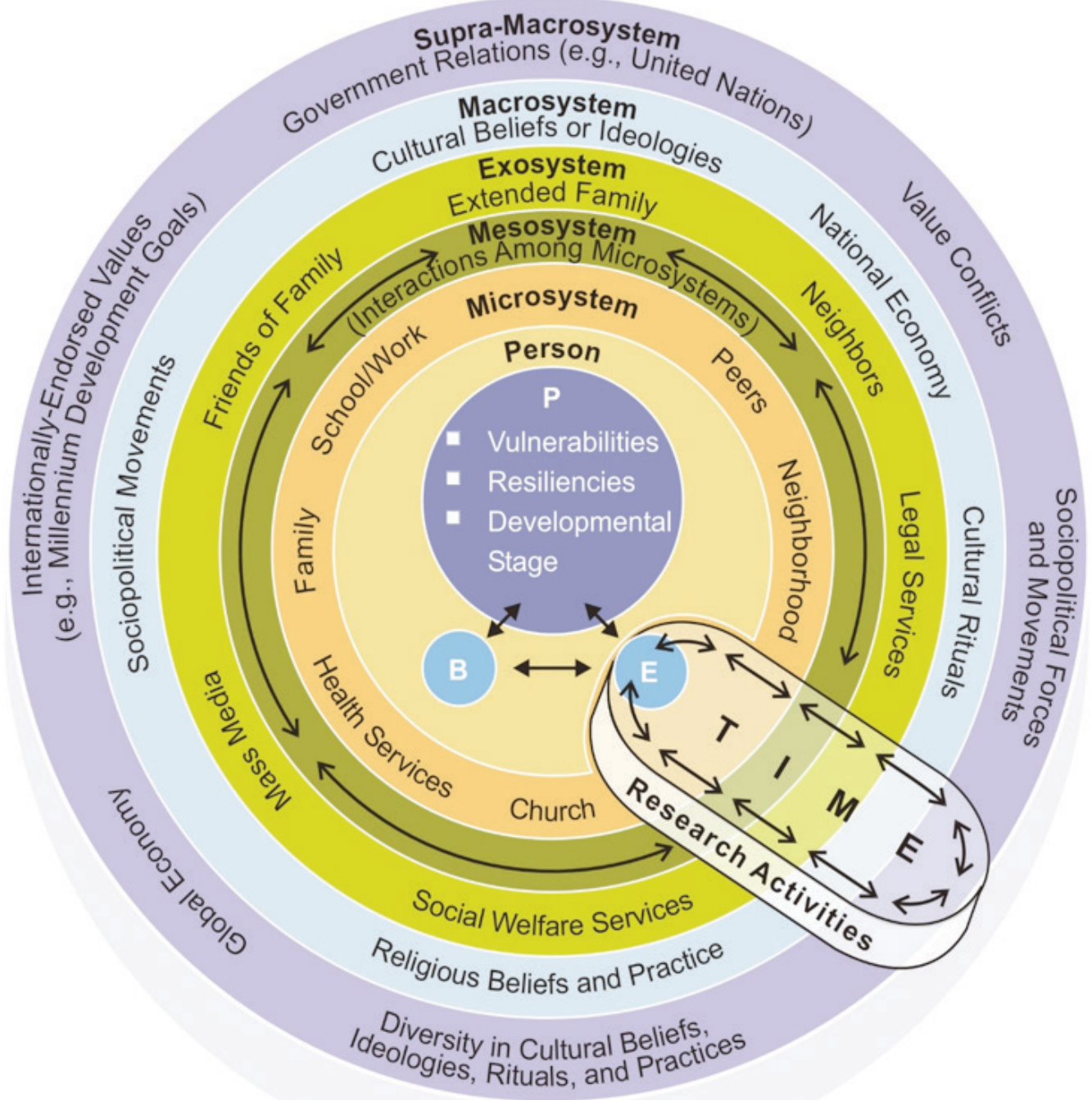

Note. PESM integrates the ecological systems approach, the biopsychosocial approach, and the principle of reciprocal determinism. In the middle of Figure 1, the letters $P, B$, and $E$ (denoting person factors, behavior, and environment, respectively) are connected by double-headed arrows in a triangle shape. Person factors include vulnerabilities, resiliencies, and developmental stage. Environmental factors (risks and resources) exist in each ecological system (level of analysis). In the lower right area, the oval formed with bidirectional arrows represents PESM's new temporal dimension, with reciprocal interactions among ecological systems occurring over time.

about me, without me" (Nelson, Ochocka, Griffin, \& Lord, 1998, p. 881). The participation of community stakeholders has outstanding benefits: (a) an improved match between project and community resources, needs, and values; (b) an improved sense of investment/commitment among community members; and (c) a shared sense of quality control and social accountability for the project (see: Gibbons et al., 1994; Strand, Marullo, Cutforth, Stoecker, \& Donohue. 2003; Wandersman \& Florin, 2000). However, transdisciplinary and multilevel PCAR requires great coordination: researchers from various disciplines conceptualize a complex community problem at different levels of analysis, and community stakeholders provide input at each level -- all with the common goal of 
employing a multilevel intervention that addresses a community problem in the comprehensive way. Trickett (2009) discusses challenges of multilevel interventions, which he calls multilevel communitybased and culturally situated interventions, defined as:

\footnotetext{
... interventions . . . that integrate a multilayered ecological conception of the community context, a commitment to working in collaboration or partnership with groups and settings in the community, and an appreciation of how intervention efforts are situated in local culture and context (p. 257).
}

Transdisciplinary projects are likely to incorporate multiple research designs. Experiments are valuable in demonstrating cause and effect; however, when ethical or practical matters in the community preclude an experiment, other research designs (e.g., quasi-experimental, correlational) are informative and may yield findings that justify resources to overcome ethical or practical matters that initially precluded use of an experimental design. To assess outcome and/or process variables associated with transdisciplinary and multilevel interventions, we recommend a blend of quantitative and qualitative approaches. Quantitative assessment (e.g., well-validated psychometric instruments) can facilitate a precise documentation of changes in an outcome or process variable over time, whereas qualitative assessment may yield (a) a more in depth understanding of the underlying reasons for a change, (b) a context for identifying multiple interpretations, meanings, or implications of a change, and/or (c) emergent themes (i.e., previously unrevealed project characteristics or patterns in the findings that warrant further consideration). Linney (2000) describes methods for assessing community contexts and constructs across ecological systems, and Chan (1998) provides "a framework for organizing, evaluating, and developing constructs . . . in multilevel research" (p. 234; also see Zimmerman, 2000). To interpret information across sources, Van de Ven (2007) recommends the method of triangulation, which broadly examines results from various sources to identify themes. When convergence occurs, such "reliability provides confidence in having a valid representation of the ... domain" (p. 285); when contradiction occurs, it suggests that (a) there is bias in one or more informational sources, (b) there are errors (or outliers) in one or more sources, or (c) "different . . . sources tap different dimensions of the domain ... or phenomenon ( $\mathrm{p}$. 285).

Finally, in this discussion of transdisciplinarity and multilevel interventions, it is natural to men- tion that the characteristics of PESM appear to be consistent with new approaches to epistemology. For instance, the Mode 2 Production of Knowledge (Gibbons et al., 2003) recommends: (a) producing knowledge in a context of application; (b) pursuing transdisciplinarity; (c) emphasizing reflexivity (reciprocity among stakeholders); (d) acknowledging social accountability; and (e) embracing multiple criteria (academic and non-academic) for research quality control.

\section{PESM and the Delineation of Project Evaluation Variables}

PESM's broad (multisystem) framework facilitates the identification of project evaluation variables for community-engaged scholarship. The concept of psychopolitical validity (Prilleltensky, 2008) is helpful in distinguishing among types of outcomes. Earlier, we briefly described psychopolitical validity and its connection with PESM's emphasis on strengthening human agency. The concept of psychopolitical validity evaluates community projects by two criteria: Type 1 - Epistem$i c$, which "demands that psychological and political power be incorporated into . . interventions"; and Type II - Transformative, which "requires that interventions move beyond [alleviative or] ameliorative efforts and towards structural change" (p. 116).

For example, consider a PCAR project in a homeless shelter in which undergraduate servicelearning research assistants work alongside faculty, graduate students, community professionals, shelter staff, and volunteers to empower shelter guests. Examples of alleviative or ameliorative outcomes would be cleaning the shelter, washing the laundry, or assisting with paperwork that may be performed by volunteers in the community. Such volunteer work is laudable and necessary, and performed by gracious (highly regarded) volunteers, but: (a) we must not conflate volunteerism with servicelearning - the latter of which "represents academic work . . . and educationally meaningful community service" (Bringle et al., 2016, p. 10); and (b) the critical point for the present discussion is that the work described above (e.g., washing laundry) does not meet criteria of psychopolitical validity. In contrast, two other types of outcome variables (empowerment and transformative) do meet psychopolitical validity criteria. An example of an empowerment outcome would be a documented increase in the rate of shelter residents obtaining employment, due to (a) a faculty member establishing a computer lab (and other resources) in the shelter, so that (b) service-learning students can assist shelter guests in developing computer skills, job-searching 
skills, soft-skills, and interviewing skills. Examples of transformative outcomes would include: (a) documented efficacy of the PCAR project in helping to prevent chronic homelessness; (b) successful adaptations of the project in other communities; or (c) eventual influence on public policy regarding the necessity of providing growth opportunities in shelters. Regarding the latter example of transformative outcomes, Minkler and Freudenberg (2010) discuss PCAR's potential influence on public policy:

\begin{abstract}
[PCAR] can be an important tool in efforts to move from data gathering and interpretation to the use of findings in ways that ... influence the lives of a large number of people. Policyfocused [PCAR] can identify, make visible, and legitimize issues so that they ... are placed on the public's agenda. It can ... help partnership members bring the attention of the mass media to long ignored issues - or newly uncovered problems - based on findings that are ... newsworthy and grounded in strong evidence. (pp. 290-291)
\end{abstract}

In sum, three categories of outcomes variables are recognized: alleviation or ameliorative, empowerment, and transformative.

None of the conceptual models critiqued in this article identified the wide array of process variables recognized in PESM. Frazier, Tix, and Barron (2004) explain that a moderator variable "alters the direction or strength of the relation between a predictor and an outcome" (p. 116) and addresses questions of "when" or "for whom" a variable has an effect. A moderating effect is "an interaction whereby the effect of one variable depends on the level of another" (p. 116). For example, an intervention for homeless individuals may be effective only for those with a certain background (e.g., absence of substance abuse). In contrast, a mediating variable "explains the relation between a predictor and an outcome" (p. 116), so research on mediators attempts to answer "how" or "why" a factor influences an outcome. A mediator is the "mechanism through which a predictor influences an outcome variable" (Frazier et al., p. 116). For example, the efficacy of an intervention that assists people transitioning out of homelessness may depend on whether the intervention fosters in homeless people a sense of agency (e.g., self-efficacy, empowerment).

Process research can also determine if a project was implemented as planned. Because the focus is on "implementation of the strategy itself" (Stoecker et al., 2010, p. 178), we will use the term implementation checks for such process variables. For instance, suppose that a project to assist homeless shelter residents incorporates a number of features hypothesized (or known) to be necessary for success (e.g., effective interventions, adequate number of intervention hours per week); in this example, implementation checks would assure that these features are in the place as the project is put into practice. In addition, process research can confirm that fidelity criteria are met as an intervention is implemented over time. "Fidelity may be defined as the extent to which delivery of an intervention adheres to the protocol or program model originally developed" (Mowbray, Holter, Teague, \& Bybee 2003. p. 315). Finally, process research addresses sustainability concerns. As Shediac-Rizkallah and Bone (1998) note, "Project sustainability is defined. . . as the capacity of a project to continue to deliver its intended benefits over . . time" (p. 91), which requires "power to . . . adapt . . . to new needs and circumstances" (p. 93). What we call sustainability process measures may include indicators of future funding, ongoing program benefits, maintenance of collaborative network, and institutional or organizational commitment. In sum, we recognize several types of process variables: mediators, moderators, implementation checks, fidelity criteria monitoring, and sustainability measures.

\section{Enhancing Resiliency and Reducing Vulnerability in Community Members}

At the individual level, we recommend multilevel interventions that enhance resiliency and reduce vulnerability in community members. In particular, given that (a) PESM emphasizes the notion that individuals play a role in the construction of their own environments, (b) community-engaged scholars work on the assumption that community members have the capability to create change in the community, and (c) the concept of psychopolitical validity is central to community research, we recommend designing interventions for community members that enhance human agency, i.e., "the power to originate and intentionally execute decisions and actions for some given purpose" (Reeb \& Folger, 2013, p. 403). Agency-related constructs include self-efficacy, empowerment, locus of control, hope, learned helplessness, alienation, competence, and self-sufficiency. Sourcebooks provide a wide variety of measures of constructs related to both resiliency (including agency) and vulnerability (e.g., Robinson et al., 1991).

\section{Reducing Environmental Risks and Enhancing Environmental Resources}

We recommend transdisciplinary (and multilevel) interventions designed to reduce environmen- 
tal risks and/or enhance environmental resources. This involves a number of daunting challenges: (a) identifying and defining each facet of a target risk (e.g., neighborhood violence) or a target resource (e.g., access to health care); (b) organizing a transdisciplinary team dedicated to the development, implementation, and evaluation of a multilevel intervention for a target risk or resource; (c) coordinating discipline-specific interventions to enhance complementarity among outcomes across systems; and (d) developing a strategy for multilevel impact assessment.

Rhodes (2002) introduced the concept of risk environment. The concept recognizes two key environmental dimensions: (a) type of environment (physical, social, economic, and policy) and (b) levels of environmental influence (micro and macro). Further, two mechanisms of environmental risk are posited: (a) susceptibility (likelihood of harm from risk factor); and (b) vulnerability (degree of potential harm from risk factor). Finally, Rhodes (2002) recommends interventions to pursue "situational or structural change" that "maximize harm reduction effect" or "remove environmental obstacles to maximizing harm reduction effect" (p. 91). This framework may also be applicable to projects that enhance resources; that is, Rhode's concept could be adapted to formulate a concept of resource empowering environment, with the term susceptibility replaced by opportunity (likelihood of benefit from a resource), the term vulnerability replaced by $\mathrm{ca}$ pacity for benefit (degree of potential benefit from a community resource), and a corresponding development of interventions that pursue situational or structural change that maximizes resources and opportunities to access (and benefit from) them. Rhodes (2009) emphasizes a "focus for change to social situations and structures" (p. 91); therefore, the reader is referred to the aforementioned work by Minkler and Freudenburg (2010), who discuss the potential of PCAR for policy change initiatives.

\section{Temporal Dimension: Process and Outcome Variables in Interdependent Systems Over Time}

PESM represents a comprehensive array of complex systems (individual to global), which may prevent us from overlooking important project outcomes, especially ones that are subtle, unintended, or emerging over time. As the outcomes (impacts) of a community-engaged scholarship project occur, PESM recognizes numerous possibilities: (a) some outcomes may be intended, while others may be unintended; (b) some outcomes may be positive in certain systems, but neutral or negative in other systems; (c) when outcomes of a project occur across interdependent systems, their effects may complement or detract from one another; (d) proximal outcomes (i.e., at individual or organizational levels) may be detected early, with broader (and distil) outcomes (i.e., at community and societal levels) not detectable until later (Stoecker et al., 2010); (e) the implementation, efficacy, and sustainability of an ongoing community-engaged scholarship project is influenced proximal events (e.g., changes in funding status, changes in institutional policies) as well as sociohistorical events (e.g., changes in the economy, changes in international relations); and (f) a period of time may be necessary for a project to mature to the point of meeting criteria of psychopolitical validity (Prilleltensky, 2008). Research recommendations revolving around the temporal dimension are provided below.

First, prospective longitudinal research is needed, accompanied by: (a) identification of project evaluation variables associated with specific systems of interest; (b) assessment of different types of outcome variables and process variables (depending on the scope of the project) across systems of interest; and (c) attempts to understand change via research examining the links among sets of process variables and outcome variables across systems and over time.

Second, we generally recommend a sequential assessment strategy that: (a) initially examines hypotheses related to proximal (individual and organizational) outcomes; (b) monitors factors that influence the project's efficacy, fidelity, and sustainability; and (c) follows up to identify any possible "historical progression . . . from individual impacts to societal impacts" (Stoecker et al., 2010, p. 191).

Third, with PESM as a framework, researchers will formulate hypotheses regarding (a) the influence of a project's interventions on outcomes and/ or (b) the processes (i.e., the underlying mechanisms) responsible for changes in outcomes. In doing so, we recommend that the hypotheses be driven by system-specific theories of change known to successfully explain how changes occurs in targeted outcome variables in the particular system(s) of interest. To clarify what we mean by a systemspecific theory of change, consider two examples representing different systems (levels of analysis): At the individual level, Prochaska, Wayne, and Velicer (1997) provided a transtheoretical model of health behavior change, which identified stages of change readiness, as well as intervention strategies to assist individuals in progressing from one stage to the next and thereby establish behavioral patterns that improve physical health. At the organizational level, Batras, Duff, and Smith (2014) discuss the applications of influential theories of 
organizational change to the "development and success of health promotion initiatives" (p. 231) in the U.S. and elsewhere. (Notice that, in each example, an intervention representing an application of a system-specific theory of change yielded outcomes in multiple systems, e.g., organizational changes can potentially promote health in individual community members.)

Regarding the temporal dimension of PESM, we want to emphasize that PESM is not meant to replace any system-specific theories of change; instead, we hope that PESM will encourage community-engaged scholars to become increasingly aware of theories of change at various levels of analysis. PESM is a broad integrative framework that informs and guides: (a) the development of transdisciplinary (and multilevel) interventions, with the recommendation that each system-specific intervention represent an application of a theory of change that coincides with that particular system (and relevant academic discipline); (b) the coordination of multilevel interventions (representing different disciplines) to assure complementarity among outcomes across systems; (c) the assessment of process and outcome variables; and (d) the identification of connections (empirical and conceptual) among project variables across systems and over time.

\section{Respect for Diversity and Awareness of Privilege}

PESM may advance our understanding of, and respect for, diversity. The principles of equifinality and multifinality, as incorporated in PESM, maintain that (a) diverse pathways may eventuate in similar outcomes and (b) the influence of one factor depends on the effects of the constellation of other factors. Thus, in addition to understanding and respecting outcome diversity (current differences in outcomes among people), PESM yields a deeper appreciation for underlying diversity in developmental pathways. A better understanding of how people may experience the same outcome via different pathways, accompanied by a recognition of the various types of obstacles that different people encounter in their development, may facilitate respect for diversity, awareness of privilege, communication, trust, reciprocity, and power sharing - all of which are necessary for successful, sustainable campus-community collaborations.

\section{Summary and Conclusion}

This article described the Psycho-Ecological Systems Model (PESM), which was developed to inform and guide community-engaged scholar- ship. Grounded in General Systems Theory (GST), PESM integrates three conceptual developments: the ecological systems approach, the biopschosocial model, and the principle of reciprocal determinism.

As a guide for community-engaged scholarship, PESM recognizes a wide array of systems (individual to international/global) and it conceptualizes the reciprocal interactions among systems. Within this broad framework, PESM delineates (and differentiates) the various types of outcome and process variables in community-engaged scholarship. Further, PESM incorporates a temporal dimension intended to assist the community-engaged scholar in the following ways: (a) identifying proximal events (e.g., funding) and distal (sociohistorical) events (e.g., economy, international events, globalization) that influence a project's sustainability; (b) monitoring the trajectory of a project's effects as they emerge, unfold, and proliferate over time; and (c) gauging the project's growth toward the development of interventions that meet the criteria of psychopolitical validity.

As PESM is used to guide and inform each phase of a community-engaged scholarship project (conceptualization, planning, development, implementation, and evaluation), we hope that it encourages the scholar-practitioner to incorporate: (a) transdisciplinary teamwork; (b) a participatory approach; (c) preparation for multilevel interventions and assessment; (d) preparation to design interventions that meet criteria of psychopolitical validity; (e) respect for diversity, and (f) heightened awareness of time-related factors that influence the project's sustainability (and changes in outcomes over time).

\section{References}

Anderson, R. E., Carter, I., \& Lowe, G. R. (2007). Human behavior in the social environment: A social systems approach (5 $5^{\text {th }}$ ed.). New York: Aldine De Gruyter.

Bailis, L. N., \& Ganger, T. (2006). A framework for further research: The community impacts of service learning. In Growing to greatness 2006 (pp. 67-72). St. Paul, MN: National Youth Leadership Council. Retrieved from http://www.peecworks.org/PEEC/ PEEC_Research/01795BFB-001D0211.1/growing\%20to\%20greatness\%202006.pdf

Bandura, A. (1978). The self system in reciprocal determinism. American Psychologist, 33(4), 344-358.

Bhattacharyya, J. (2004). Theorizing community development. Journal of Community Development Society, 34(2), 5-34.

Batras, D., Duff, C., \& Smith, B. J. (2914). Organizational change theory: Implications for health promotion practice. Health Promotion International, 31(1), 231-241 
Boulding, K. E. (1956). General systems theory: The skeleton of science. Management Science, 2(3), 197208.

Bringle, R. G., Reeb, R. N., Brown, M. A., \& Ruiz, A. I. (2016). Service learning in psychology: Enhancing undergraduate education for the public good. Washington, DC: American Psychological Association.

Bronfenbrenner, U. (1979). The ecology of human development: Experiments by nature and design. Cambridge, MA: Harvard University Press.

Bronfenbrenner, U. (1993). Ecological models of human development. In M. Gauvain, \& M. Cole (Eds.). Readings on the development of children (2nd Ed) (pp. 3743). NY: Freeman.

Chan, D. (1998). Functional relations among constructs in the same content domain at different levels of analysis: A typology of composition models. Journal of Applied Psychology, 83(2), 234-246

Cicchetti, D., \& Cohen, D. J. (1995). Perspectives on developmental psychopathology. In D. Ciccheti \& D. Cohen (Eds.), Developmental psychopathology: Vol. 1. Theories and methods (pp. 3-20). New York: Wiley.

Colombo, J. (1982). The critical period concept: Research, methodology, and theoretical issues. Psychological Bulletin, 91(2), 260-275.

Frazier, P. A., Tix, A. P., \& Barron, K. E. (2004). Testing moderator and mediator effects in counseling psychology research. Journal of Counseling Psychology, 51(1), 115-134.

Gibbons, M., Limoges, C., Nowotny, H., Schwartzman, S., Scott, P., \& Trow, M. (1994). The new production of knowledge: The dynamics of science and research in contemporary societies. Thousand Oaks, CA: Sage.

Harkavy, I., \& Hartley, M. (2010). Pursuing Franklin's dream: Philosophical and historical roots of servicelearning. American Journal of Community Psychology, 46(3-4), 418-427.

Hawe, P. (2017). The contribution of social ecological thinking to community psychology: Origins, practice, and research. In M. A. Bond, I. Serrano-García, C. B. Keys, \& M. Shinn (Eds.), APA handbooks in psychology. APA handbook of community psychology: Theoretical foundations, core concepts, and emerging challenges (pp. 87-105). Washington, DC: American Psychological Association.

Kiesler, D. J. (2000). Beyond the disease model of mental disorders. Westport, CT: Praeger Publishers.

Koestler, A. (1967). The ghost in the machine. New York: The Macmillan Company.

Lenneberg, E. H. (1967). Biological foundations of language. New York: John Wiley.

Linney, J. A. (2000). Assessing ecological constructs and community context. In J. Rappaport \& E. Seidman (Eds.), Handbook of community psychology (pp. 647-668). New York: Kluwer Academic/Plenum Publishers.

Marullo, S., Cooke, D., Willis, J., Rollins, A., Waldref, V. (2003). Community-based research assessments: Some principles and practices. Michigan Journal of Community Service Learning, 9(3), 57-68.
Minkler, M., \& Freudenberg, N. (2010). From community-based participatory research to policy change. In H. E. Fitzgerald, C. Burack, \& S. D. Seifer (Eds.), Handbook of engaged scholarship: Contemporary landscapes, future directions: Volume 2: Community-campus partnerships (pp. 275-294). East Lansing, MI: Michigan State University Press.

Minkler, M., \& Wallerstein, N. (2003). Communitybased participatory research for health. San Francisco: Jossey-Boss.

Mowbray, C. T., Holter, M. C., Teague, G. B., \& Bybee, D. (2003). Fidelity criteria: Development, measurement, and validation. American Journal of Evaluation, 24(3), 315-340.

Nelson, G., Ochocka, J., Griffin, K., \& Lord, J. (1998). "Nothing about me, without me": Participatory action research with self-help/mutual aid organizations for psychiatric consumer survivors. American Journal of Community Psychology, 26(6), 881-912. Sterling, VA: Stylus.

Niehaus, E., \& Crain, L. K. (2013). Act local or global?: Comparing student experiences in domestic and international service-learning programs. Michigan Journal of Community Service Learning, 20(1), 31-40.

Prilleltensky, I. (2008). The role of power in wellness, oppression, and liberation: The promise of psychopolitical validity. Journal of Community Psychology, 36(2), 116-136.

Prochaska, J. O., \& Velicer, W. F. (1997). The transtheoretical model of health behavior change. American Journal of Health Promotion, 12(1), 38-48.

Reeb, R. N., Bohardt, D., Alpert, J., Maloy-Kidder, M., Daniels-Sommers, S., Cortner, C. et al. (2015, November). Behavioral activation in homeless shelters: A transdisciplinary and participatory community action research project: A community stakeholder research team presentation. Symposium presented at the International Association for Research on ServiceLearning and Community Engagement, Boston, MA.

Reeb, R. N., Davidson, W., Majka, T., Majka, L., Rosing, H., Steel, A. et al. (2011, November). Psychoecological systems model of engaged scholarship and service-learning research: Multidisciplinary research applications. Symposium presented at the annual conference of the International Association for Research on Service-Learning and Community Engagement, Chicago, Illinois.

Reeb, R. N., Elvers, G., Talbott, A., Majka, T., Bohardt, D., Gretak, A. et al. (2016, November). A human rights approach in research on service-learning, communityengagement, and advocacy. Symposium presented at the annual conference of the International Association for Research on Service-Learning and Community Engagement, New Orleans, LA.

Reeb, R.N., Farmer, C., Glendening, Z., \& Kinsey, R. (2014, August). Application of psycho-ecological systems model: Behavioral activation in homeless shelters. Poster presented at the annual meeting of the American Psychological Association, Washington, DC.

Reeb, R.N., Farmer, C., Glendening, Z., Kinsey, R., El- 
vers, G., Farnsworth, T. et al. (2014, May). Effects of behavioral activation in a homeless shelter for men. Poster presented at the annual meeting of the Midwestern Psychological Association, Chicago, IL.

Reeb, R. N., \& Folger, S. F. (2013a). Community outcomes in service learning: Research and practice from a systems perspective. In P. H. Clayton, R. G. Bringle, \& J.A. Hatcher (Eds.), Research on service-learning: Conceptual models and assessment (pp. 389-418). Sterling, VA: Stylus Publishing.

Reeb, R. N., \& Folger, S. F. (2010, October). The psychoecological systems model for engaged scholarship and community-oriented service-learning research. Poster presented at the annual meeting of the International Association for Research on Service-Learning and Community Engagement, Indianapolis, IN.

Reeb, R. N., Folger, S. F., Langsner, S., Ryan, C., \& Crouse, J. (2010). Self-efficacy in service-learning community action research: Theory, research, and practice. American Journal of Community Psychology, 46(3-4), 459-471.

Reeb, R. N., Folger, S. F., Steel, A. L., Mason, S. E., Stayton, L. E., \& Ufholz, K. E.(2011, August). Psycho-ecological systems model for participatory community action research: Evidence of validity and practical utility. Poster presented at the annual meeting of the American Psychological Association, Washington D.C.

Reeb, R. N., Gahimer, J. L., Folger, S.F., Steel, A., Mason, S., Stayton, L. et al. (2011, September). Psychoecological systems model for engaged scholarship and service-learning: Theory, research, and multidisciplinary applications. Paper presented at the Fourth International Symposium on Service-Learning, Ningbo, Zhejiang, China.

Reeb, R. N., Gahimer, E., Snow, N., \& Glendening, Z. (2013, November). Recent applications of the psychoecological systems model for engaged scholarship and service-learning research. Poster presented at the Fifth International Symposium on Service-Learning, Stellenbosch, South Africa.

Reeb, R. N., Glendening, Z., Farmer, C., Snow, N. L., \& Elvers, G. (2014, October). Behavioral activation in a homeless shelter: An interdisciplinary service-learning community-based research project. Paper presented at the International Association for Research on ServiceLearning Community Engagement, New Orleans, LA.

Reeb, R. N., Majka, T., \& Majka, L., Coder, K., Snow, N. Stayton., L. et al. (2012, September). The psychoecological systems model as a guide for engaged scholarship and service-learning research. Symposium presented at the annual meeting of the International Association for Research on Service-Learning and Community Engagement, Baltimore, MD.

Reeb, R., Majka, L., Majka, T., Mason, S., Steel, A., Stayton, L. et al. (2011, February). Psycho-ecological systems model for engaged scholarship and servicelearning research and practice. Symposium presented at the Southwestern Ohio Council for Higher Education Service Learning Conference, Cedarville, Ohio.

Reeb, R. N., O’Koon, B., Folger, S., \& Snow, N. (2017,
September). Critique of conceptual models guiding engaged scholarship and service-learning research: Towards a general systems theory approach. Paper presented at the International Association for Research on Service-Learning and Community Engagement, Galway, Ireland.

Reeb, R.N., Snow, N., Susdorf, G., Thomas, S., \& Lynn, N. (2013, May). Engaged scholarship for homelessness: Student and community outcomes. Poster presented at the annual meeting of the Midwestern Psychological Association, Chicago, Illinois.

Reeb, R. N. Steel, A., Mason, S., Stayton, L., \& Ufholz, K. (2011, February). Psycho-ecological systems model for engaged scholarship and service-learning research: Application to Homelessness. Paper presented at the Southwestern Ohio Council for Higher Education Service Learning Conference, Cedarville, Ohio.

Rhodes, T. (2002). The "risk environment": A framework for understanding and reducing drug-related harm. International Journal of Drug Policy, 13(2), 85-94.

Robinson, J. P., Shaver, P. R., \& Wrightsman, L. S. (Eds.). (1991). Measures of personality and social psychological attitudes, (Vol. 1). New York: Academic Press.

Shediac-Rizkallah, M. C., \& Bone, L. R. (1998). Planning for sustainability of community-based health programs: Conceptual frameworks and future directions for research, practice and policy. Health Education Research: Theory and Practice, 13(1), 87-108.

Stoecker R., Beckman, M., \& Min, B. H. (2010). Evaluating community impact of higher education civic engagement. In H. E. Fitzgerald, C. Burack, \& S. D. Seifer (Eds.) Handbook of engaged scholarship (Vol 2, pp. 177-196). East Lansing: Michigan State University Press.

Strand, K., Marullo, S., Cutforth, N., Stoecker, R., \& Donohue, P. (2003). Community-based research and higher education. San Francisco: John Wiley \& Sons.

Tress, B., Tress, G., \& Fry, G. (2006). Defining concepts and the process of knowledge production in integrative research. In B. Tress, G. Tress, G. Fry, \& P. Opdam (Eds.), From landscape research to landscape planning: Aspects of integration, education, and application (pp. 13-26). Dordrecht, The Netherlands: Springer.

Trickett, E. J. (2009). Multilevel community-based culturally situated interventions and community impact: An ecological perspective. American Journal of Community Psychology, 43, 257-266.

Van de Ven, A. H. (2007). Engaged scholarship: A guide for organizational and social research. Oxford, UK: University Press.

Von Bertalanffy, L. (1968). General systems theory: Foundations, development, and applications. New York: George Brazillier.

Von Bertalanffy, L. (1972). The history and status of general systems theory. The Academy of Management Journal. 15(4), 407-426.

Wandersman, A., \& Florin, P. (2000). Citizen participation and community organizations. In J. Rappaport \& E. Seidman (Eds.), Handbook of community psychol- 
ogy (pp. 247-272). New York: Kluwer Academic/Plenum Publishers.

Wells, J. (2017). A theoretically grounded framework for integrating the scholarship of teaching and learning. Journal of the Scholarship of Teaching and Learning, 17(2), 24-34.

Zimmerman, M. A. (2000). Empowerment theory: Psychological, organizational, and community levels of analysis. In J. Rappaport \& E. Seidman (Eds.), Handbook of community psychology (pp. 43-63). New York: Kluwer Academic/Plenum Publishers.

\section{Authors}

ROGER N. REEB (rreeb1@udayton.edu) received his doctorate in clinical psychology from Virginia Commonwealth University, after completing the pre-doctoral internship at the Brown University Internship Consortium. He is a professor of psychology and Roesch Endowed Chair in the Social Sciences at the University of Dayton. Reeb joined the faculty at the University of Dayton in 1993, where he served as Director of Graduate Programs in Psychology (2006-2014), and received a number of awards (Alumni Award in Teaching; Outstanding Faculty Service-Learning Award; and Service-Learning Faculty Research Award). From the American Psychological Association, he received a Dissertation Award and the Springer Award for Excellence in Research in Rehabilitation Psychology (Division 22). Recently, Reeb was selected to serve on the American Psychological Association's Work Group on Citizen Psychologists for President-Elect (Jessica Henderson Daniel). His research focuses on homelessness, psychopathology, clinical-community psychology, and outcomes of service-learning pedagogy for students and community.

NYSSA L. SNOW-HILL (nsnow@email.sc.edu) received her M.A. degree in clinical psychology from the University of Dayton in 2013. Currently, she is a doctoral candidate in clinical-community psychology at the University of South Carolina. Her research focuses on understanding people's complex attitudes toward homelessness and developing strategies for changing negative attitudes. In addition, she works with community initiatives that serve unaccompanied/homeless youth and assists those organizations with the use of data to develop comprehensive living programs.

SUSAN F. FOLGER (susanffolger@gmail.com) received her M.A. degree in clinical psychology from the University of Dayton. She then received her Ph.D. in clinical psychology at Miami University, after completing the pre-doctoral internship at the Pennsylvania State University's Center for Counseling and Psychological Services. Folger also completed a postdoctoral fellowship at the University of Delaware's Center for Counseling and Student Development. Currently, she is a staff member at Ohio University's Center for Counseling and Psychological Services. She enjoys working with college students to promote their well-being and growth. Particular clinical interests include interpersonal violence, grief and loss, social justice, and identity development.

ANNE STEEL (asteel@huskers.unl.edu) received her M.A. degree in clinical psychology from the University of Dayton and is now a doctoral candidate in clinical psychology at the University of Nebraska-Lincoln. She is currently completing a pre-doctoral internship at the Durham VA Medical Center. In her research, she investigates the role of social factors (e.g., social support, responses to disclosure) in victims' recovery from interpersonal violence.

LAURA STAYTON (laura.e.stayton@wmich. edu) received her M.A. degree in clinical psychology from the University of Dayton. She then received her doctoral degree in clinical psychology at Western Michigan University, after completing the pre-doctoral internship at Cincinnati VA Medical Center. Currently, she is a postdoctoral fellow at the Cincinnati VA Medical Center. Her fellowship focuses on the treatment of PTSD and homeless Veterans. She is actively involved in research projects evaluating the effectiveness of evidence-based treatments for PTSD and possible mechanisms of action within available treatments.

CHARLES A. HUNT (huntc1@udayton.edu) received his M.A. degree in clinical psychology from the University of Dayton. At present, he is the post-graduate research assistant in Community Engagement at the University of Dayton. In part, this position involves work in the Montgomery County Office of Ex-Offender Reentry, attempting to bridge the gap between homeless shelters and the Reentry Career Alliance Academy and assisting to develop new evidence based practices to reduce recidivism. His research interests include diverse and disadvantaged populations, the role of emotions in mental health functioning, and general factors in effective therapeutic practices.

BERNADETTE O'KOON (bernadetteokoon@ gmail.com) received her Juris Doctor Degree from the Louis D. Brandeis School of Law at the University of Louisville. While working as an attorney, O'Koon became interested in how trauma is influenced by individual, familial, legal/political, and social factors. She attended the M.A. Program in Clinical Psychology at the University of Dayton, and is now a doctoral student at the Wright State University School of Professional Psychology. In 
her dissertation, O'Koon plans to explore the relationship between self-compassion, religiosity, and LGBTQ self-stigma. She is also researching internalized oppression within the therapeutic relationship. O'Koon has a passion for social justice and gestalt therapy.

ZACHARY GLENDENING (zachary.s.glendening@vanderbilt.edu) received his M.A. degree in clinical psychology from the University of Dayton and his M.S. in community research and action from Vanderbilt University. Currently, he is a doctoral student in community research and action at Vanderbilt University. His current research focuses on preventing homelessness and housing stability, particularly among families including members with disabilities. 